\title{
The role of prostacyclin in the interaction of endothelial cells and eosinophil granulocytes
}

Viktória Kónya ${ }^{1}$, Eva M Sturm ${ }^{1}$, Zoltán Bálint ${ }^{2}$, Martin Krenn ${ }^{3}$ and Ákos Heinemann*1

\author{
Address: ${ }^{1}$ Institute of Experimental and Clinical Pharmacology, Medical University of Graz, 8010 Graz, Austria, ${ }^{2}$ Department of Anaesthesiology, \\ Medical University of Graz, 8036 Graz, Austria and ${ }^{3}$ Institute of Pharmacology and Toxicology, University of Graz, 8010 Graz, Austria \\ Email: Ákos Heinemann* - akos.heineman@meduni-graz.at \\ * Corresponding author
}

from I4th Scientific Symposium of the Austrian Pharmacological Society (APHAR)

Innsbruck, Austria. 21-22 November 2008

Published: 5 November 2008

BMC Pharmacology 2008, 8(SuppI I):AI3 doi:I0.I|86/I47|-22I0-8-SI-AI3

This abstract is available from: http://www.biomedcentral.com/I47I-22I0/8/SI/AI3

(C) 2008 Kónya et al; licensee BioMed Central Ltd.

\section{Background}

Enhanced eosinophil migration from the blood into the tissue is a hallmark of bronchial asthma and other allergic diseases. So far, very little is known how the function of vascular endothelial cells is modulated in this process. Our aim was to characterize the role of prostacyclin $\left(\mathrm{PGI}_{2}\right)$ in endothelial function and endothelium-eosinophil interaction.

\section{Materials and methods}

Cell interaction studies, like adhesion and transmigration assays, were performed with freshly isolated human blood eosinophils on confluent layers of human lung microvascular endothelial cells. The changes in endothelial monolayer integrity were detected by means of transendothelial electrical resistance and by fluorescence microscopy.

\section{Results}

Under basal conditions, the major prostaglandin released by human microvascular endothelial cells is $\mathrm{PGI}_{2}$. Exogenous $\mathrm{PGI}_{2}$ markedly attenuated the migration of isolated eosinophils through cell-free filters. This effect was prevented by the IP receptor antagonist Cay10441 and the adenylyl cyclase inhibitor SQ29548. Treatment of endothelial cells with diclofenac, a non-selective COX inhibitor, abolished the $\mathrm{PGI}_{2}$ production which was accompanied by enhanced eosinophil adhesion to endothelial monolayers. Similarly, the transmigration of eosinophils through endothelial monolayers was enhanced by diclofenac. The diclofenac treatment itself decreased the electrical resistance of endothelial monolayers and compromised the intercellular cell junctions as visualized by VE-cadherin staining.

\section{Conclusion}

Based on these observations, we conclude that the basal synthesis of $\mathrm{PGI}_{2}$ by endothelial cells can down-regulate the endothelial adhesion and transmigration of eosinophils. Furthermore, endogenous $\mathrm{PGI}_{2}$ seems to be important for the maintenance of endothelium barrier function. These results suggest that $\mathrm{PGI}_{2}$ may have a protective role in the case of allergic inflammation and provide a novel explanation for previous observations that IP knock-out mice show enhanced eosinophilic inflammation in response to allergen [1].

\section{References}

I. Takahashi Y, Tokuoka S, Masuda T, Hirano Y, Nagao M, Tanaka H, Inagaki N, Narumiya S, Nagai H: Augmentation of allergic inflammation in prostanoid IP receptor deficient mice. Br J Pharmacol 2002, 137:315-322. 